\title{
TIPIZZAZIONE MOLECOLARE DELLA \\ RESISTENZA A RIFAMPICINA E ISONIAZIDE IN CEPPI MDR DI M. tubercolosis ISOLATI IN ITALIA.
}

\author{
Cavallerio P.', Piana F.'-2, Matinato C. ${ }^{3}$, Migliori G.B. ${ }^{4}$, \\ Penati V.' Lacchini C. ${ }^{2}$, Cirillo D.' \\ 'Emerging Bacterial Infection Unit, San Raffaele Hospital, \\ via Stamira d'Ancona 20, 20127 Milan, Italy \\ 2 Istituto Villa Marelli, Ospedale Niguarda Ca' Granda, \\ Viale Zara 81, 20159, Milan, Italy \\ 'Laboratorio Sanità Pubblica ASL Città di Milano \\ ${ }^{4} \mathrm{WHO}$ collaborating centre F.S. Maugeri-Tradate
}

Introduzione. Il numero di ceppi resistenti a isoniazide (INH) e rifampicina (RIF), definiti come multi resistenti, è in continuo aumento.

Scopo del seguente lavoro, è identificare le mutazioni implicate nella resistenza a RIF e INH attraverso l'utilizzo di metodiche di biologia molecolare.

Metodi. Sono stati analizzati 146 ceppi (114 MDR) provenienti dal "Centro di Riferimento Regionale per le Micobatteriosi" Villa Marelli di Milano. La determinazione genotipica delle mutazioni che conferiscono resistenza a RIF e INH è stata eseguita attraverso due metodi: un kit commerciale (Genotype MTBDR 96-Hain Lifescience) atto a individuare mutazioni su $K a t G$ ed $r p o B$ ed una multiplex PCR "home made" disegnata per rilevare mutazioni su KatG (ser 315) e sulla regione di mabA-InHA (-15 C-T).

La sensibilità dei ceppi esaminati a RMP, INH, streptomicina, etambutolo e pirazinamide è stata valutata utilizzando il sistema BACTEC MGIT 960.

Risultati. Su 114 ceppi RIF-resistenti testati 106 (93\%) mostrano una mutazione su rpoB; la sostituzione S531L è stata riscontrata in 57 casi $(50 \%)$, altre mutazioni frequenti sono rappresentate da delezioni (31\%). Su 139 ceppi INHresistenti, il kit Genotype MTBDR ne ha evidenziati 90 che presentano mutazione sul codone 315 (61\%), mentre 49 (33\%) non sono stati riconosciuti come mutati. La multiplex PCR ha identificato come mutati 11 ceppi in più $(69 \%)$.

Conclusioni. La mutazione $\mathrm{rpoB}$ è evidenziabile in quasi tutti i ceppi RIF resistenti (93\%).

Tra i ceppi INH resistenti, la mutazione su $K a t G$ è rilevabile nel $61 \%$ dei casi utilizzando il test "Genotype MTBDR", mentre l'uso della multiplex, in grado di evidenziare mutazioni anche sulla regione di mabA-InHA, consente di identificare 101/139 ceppi INH resistenti (69\%). L'approccio molecolare nello studio della resistenza verso RIF, ma non verso INH, ha una elevata sensibilità su ceppi di $M$. tubercolosis isolati in Italia. 